DOI 10.35694/YARCX.2020.49.1.017

\title{
МЕТОДЫ ЗАМЕРА
}

НАДПОРШНЕВЫХ ЗАЗОРОВ АВТОТРАНСПОРТНЫХ ДИЗЕЛЬНЫХ ДВИГАТЕЛЕЙ

\section{В УСЛОВИЯХ ЭКСПЛУАТАЦИИ}

\section{Автотранспортный дизельный двигатель, поршень, надпоршневой зазор, индекс поршня}

Automotive diesel engine, piston, over-piston clearance, piston index
Б.С. Антропов (фото)

д.Т.н., профессор, профессор кафедры автомобильного транспорта

ФГБОУ ВО «Ярославский государственный технический университет», г. Ярославль

В.В. Капралов

к.п.Н., старший преподаватель кафедры тактики

и общевоенных дисциплин

В.В. Гуменный

доцент кафедры тактики и общевоенных дисциплин

В.А. Генералов

преподаватель кафедры тактики и общевоенных дисциплин ФГБУ МО «Ярославское высшее военное училище противовоздушной обороны», г. Ярославль

Как показывает опыт эксплуатации, в большинстве случаев при ремонте двигателей ЯМ3-840, КамАЗ-740 и их модификаций в условиях эксплуатирующих организаций не соблюдаются надпоршневые зазоры, рекомендуемые заводами-изготовителями. Основной причиной этого является отсутствие информации о методах их обеспечения, предусмотренных конструкцией указанных двигателей, и методах измерения в условиях эксплуатации.

Следует напомнить, что на указанных двигателях ЯМЗ оптимальный надпоршневой зазор равен 0,94-1,34 мм, на двигателях КамАЗ - 0,92-1,27 мм [1, 2]. Несоблюдение оптимальных зазоров ведёт к следующим явлениям: при уменьшении минимального значения происходит соударение поршней с огневой поверхностью головок цилиндров (вследствие нагароотложений на них в процессе эксплуатации), приводящее к появлению стука при работе двигателя; превышение максимального значения приводит к увеличению расхода топлива и резкому возрастанию дымности отработавших газов. 
Для замера надпоршневых зазоров целесообразно использовать следующий метод: перед установкой головок на двигатель, на поршни необходимо с помощью солидола закрепить (в плоскости качания шатуна на противоположных сторонах днища) по пластине свинца толщиной не более 2 мм (по ширине и длине не более 4-5 мм). Поставить на двигатель головки цилиндров с прокладками газового стыка и затянуть их крепёж согласно требованиям завода-изготовителя. После этого сделать с помощью монтажки один оборот коленчатого вала и снять головки цилиндров. С помощью штангенциркуля замерить толщину пластин в каждом цилиндре. Действительный размер надпоршневого зазора будет равен среднему значению двух пластин каждого цилиндра. После этого делается вывод о том, как вернуть зазор в оптимальные пределы. На двигателях ЯМЗ размерный $S / D=140 / 140$ мм зазор регулируется с помощью трёх прокладок газового стыка, которые маркируются индексами 10, 20, 30, толщина которых соответственно равна 1,3, $1,5,1,7$ мм.

Недостатком рассмотренного метода является трудоёмкость процесса демонтажа и установки головок цилиндров на двигатель.

В экспериментальном цехе Ярославского моторного завода используются приспособления, позволяющие измерять надпоршневой зазор без съёма головок цилиндров. На рисунке 1 приведено приспособление для двигателей ЯМЗ, а на рисунке 2 - чертёж пластин.

В нерабочем состоянии (без усилия на рукоятке) пластины разведены, как показано на рисунке 1, т.е. находятся в одной плоскости под углом $90^{\circ}$ к оси штока. Это связано с тем, что ось отверстия под форсунку в головках цилиндров двигателей ЯМЗ совпадает с осью цилиндра двигателя.

В отверстия пластин диаметром 3 мм (рис. 2) устанавливают кусочки свинца размером $3 \times 3 \times 3$ мм и слегка расплющивают во избежание выпадения из отверстий (минимальная высота кусков свинца после расплющивания 1,5 мм). После этого нажатием на рукоятку пластины сводятся в одну плоскость с осью штока. Приспособление через отверстие под форсунку в головке вводят в цилиндр, в котором поршень находится в нижней мёртвой точке. Снимают усилие с рукоятки и приспособление поднимают вверх до упора пластины в огневую поверхность головки цилиндров, при этом пластины должны находиться в плоскости качания шатуна.

Удерживая приспособление в неподвижном состоянии, поворачивают коленчатый вал на один оборот. После этого приспособление

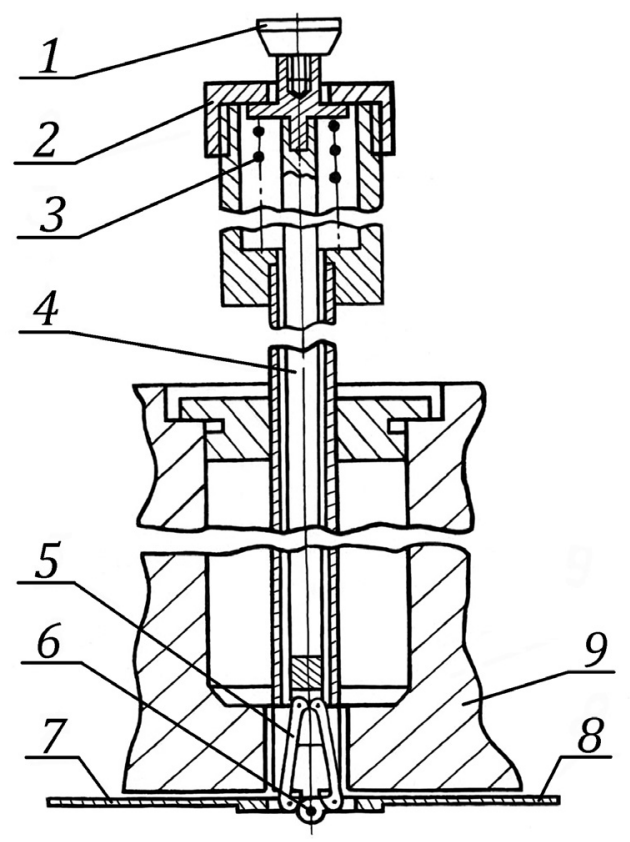

1 - рукоятка; 2 - корпус; 3 - пружина; 4 - шток; 5 - рычаг; 6 - ось; 7-8 - пластины; 9 - головка цилиндров.

Рисунок 1 - Приспособление для замера надпоршневого зазора на двигателях ЯМЗ 

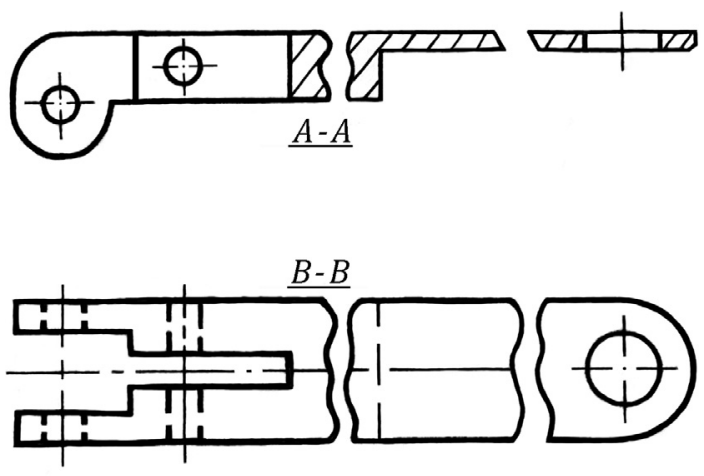

Рисунок 2 - Пластина приспособления (материал: сталь)

извлекают из цилиндра. Микрометром или штангенциркулем измеряют высоту деформированных кусков свинца, средняя высота которых соответствует действительному надпоршневому размеру.

Для двигателей КамАЗ приспособление по конструкции отлично от приспособления для двигателей ЯМЗ. Исключением является положение пластин под углом к оси приспособления, как показано на рисунке 3. Это связано с тем, что форсунки на двигателях КамАЗ вынесены за пределы крышек головок цилиндров и отверстия для них находятся под углом к осям цилиндров [3].
Рекомендуется заносить в таблицу 1 результаты измерений толщины снятых образцов с помощью верхней и нижней пластин приспособления, как это показано для двигателя КамАЗ.

Анализ замеров, приведённых в таблице, показывает, что во втором цилиндре зазор меньше нормы, а в седьмом - больше нормы. На этих цилиндрах демонтируются головки и определяются индексы поршней. На двигателях КамАЗ применяют поршни с индексом 10, 20, 30 и 40. Индекс поршня определяется расстоянием от оси отверстия пальца до его днища. При возрастании индекса указанный размер увеличивается в среднем на

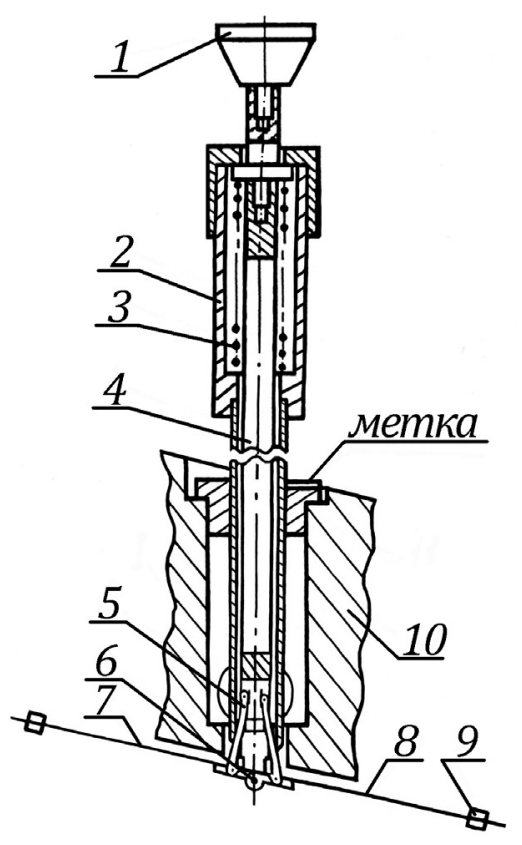

1 - рукоятка; 2 - корпус; 3 - пружина; 4 - шток; 5 - рычаг; 6 - ось; 7 и 8 - пластины; 9 - свинец; 10 - головка цилиндров.

Рисунок 3 - Приспособление для замера надпоршневого зазора на двигателях КамАЗ 
Таблица 1 - Результаты замера надпоршневого зазора в двигателе КамАЗ

\begin{tabular}{|c|c|c|c|c|c|c|c|c|}
\hline \multirow[t]{2}{*}{ Параметр } & \multicolumn{8}{|c|}{ № цилиндров } \\
\hline & 1 & 2 & 3 & 4 & 5 & 6 & 7 & 8 \\
\hline \multicolumn{9}{|c|}{ Надпоршневой зазор, замеренный пластиной, мм } \\
\hline Верхней & 1,05 & 0,84 & 1,12 & 1,00 & 1,10 & 1,20 & 1,32 & 1,16 \\
\hline Нижней & 1,07 & 0,86 & 1,14 & 1,04 & 1,12 & 1,24 & 1,36 & 1,12 \\
\hline \multicolumn{9}{|c|}{ Средняя величина надпоршневого зазора, мм } \\
\hline Значение & 1,06 & 0,85 & 1,13 & 1,02 & 1,11 & 1,22 & 1,34 & 1,14 \\
\hline \multicolumn{9}{|c|}{ Индекс поршня } \\
\hline Значение & - & 20 & - & - & - & - & 10 & - \\
\hline \multicolumn{9}{|c|}{ Индекс необходимого поршня } \\
\hline Значение & - & 10 & - & - & - & - & 20 & - \\
\hline
\end{tabular}

0,11 мм. Разница в размере между коротким поршнем (индекс 10) и длинным поршнем (индекс 40) составляет в среднем 0,33 мм.

Уточнив индексы поршней во втором и седьмом цилиндрах (табл. 1), приходим к выводу, что для обеспечения оптимального зазора необходимо заменить во втором цилиндре поршень с индексом 20 на поршень с индексом 10 (надпоршневой зазор при этом будет равен 0,85 + 0,11=0,96 мм) и в седьмом цилиндре - поршень с индексом 10 на поршень с индексом 20 (надпоршневой зазор при этом будет равен 1,34 - 0,11 = 1,23 мм). После перекомплектования поршни с шатунами устанавливают в цилиндры, в которых снова про- веряют надпоршневой зазор. Если он соответствует норме - двигатель собирают обратно.

\section{Bblвod}

Таким образом, рассмотренные нами приспособления могут быть изготовлены в условиях эксплуатации для любой модели двигателя. Отличаться они будут длиной пластин в зависимости от диаметра цилиндра и их расположением к оси цилиндра. Они позволяют проводить замер надпоршневого зазора в двигателе без демонтажа головок цилиндров, осуществлять его регулирование для достижения оптимальных значений, рекомендуемых заводами-изготовителями.

\section{Лumepamypa}

1. Антропов, Б.С. Новые автотранспортные дизели ЯМЗ [Текст] / Б.С. Антропов, Г.М. Савельев. - Ярославль: ЯИПКиПК, 1992. - 112 с.

2. Барун, В.Н. Автомобили КамАЗ: техническое обслуживание и ремонт [Текст] / В.Н. Барун, Р.А. Азаматов, Е.А. Машков и др. - 2-е изд., перераб. и доп. - М.: Транспорт, 1987. - 352 с.

3. Инновации бизнесу. Приспособление для замера надпоршневого зазора [Электронный ресурс]. Режим доступа: http://www.ideasandmore.ru/Ntrr/Details/115105 (дата обращения 25.10.2019).

\section{References}

1. Antropov, B.S. Novye avtotransportnye dizeli JaMZ [Tekst] / B.S. Antropov, G.M. Savel'ev. - Jaroslavl': JaIPKiPK, 1992. - $112 \mathrm{~s}$.

2. Barun, V.N. Avtomobili KamAZ: tehnicheskoe obsluzhivanie i remont [Tekst] / V.N. Barun, R.A. Azamatov, E.A. Mashkov i dr. - 2-e izd., pererab. i dop. - M.: Transport, 1987. - 352 s.

3. Innovacii biznesu. Prisposoblenie dlja zamera nadporshnevogo zazora [Jelektronnyj resurs]. - Rezhim dostupa: http://www.ideasandmore.ru/Ntrr/Details/115105 (data obrashhenija 25.10.2019). 